\title{
Influence of the level of maternal education on the long-term neurodevelopment outcome of Saudi infants with birth weight of 1000-1500 grams at the age of 21-24 months
}

\author{
Badr Hasan Sobaih*
}

\section{${ }^{*}$ Correspondence}

Badr Hasan Sobaih, MD, ABP

King Saud University. Department of paediatrics, King Khalid University

Hospital. Riyadh, Kingdom of Saudi Arabia.

Email: bsobaih@ksu.edu.sa

Telephone: 0966114672395

Received: Jan 22, 2019

Accepted: Apr 17, 2019

Published: May 1, 2019

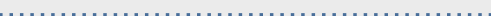

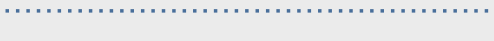

\begin{abstract}
Background: Advancements in perinatal-neonatal care in the last decades has led to improved survival rates of very-low birth weight (VLBW) infants. An association between the level of maternal education and neurodevelopmental outcome has been demonstrated in many European studies. This study evaluates the influence of maternal education level and sociodemographic status on the long-term development of Saudi VLBW infants with birth weight of 1000-1500 grams at a corrected gestational age of 21-24 months.
\end{abstract}

Method: This retrospective cohort study examined prospectively collected data from the period of 2005 to 2016 from the Neonatal Follow-up Program (NFP) at King Khalid University Hospital in Riyadh, Saudi Arabia.

Results: A total of 122 VLBW infants with a mean gestational age of 29.57 weeks and mean birth weight 1265 grams were enrolled. There was no statistically significant association between the level of maternal education and neurodevelopmental screening outcome at the age of 21-24 months according to the Bayley Infant Neurodevelopmental Screener (BINS) ( $p=0.149$ ). Bronchopulmonary dysplasia (BPD) was highly associated with cerebral palsy $(p=0.001)$ and an abnormal BINS score $(p=0.010)$.

Conclusion: There was no significant influence of the level of maternal education on the neurodevelopmental screening outcome of VLBW infants at the corrected age of 21-24 months. BPD was the strongest predictor of adverse neurodevelopmental outcome.

Keywords: Bayley Infant Neurodevelopmental Screener (BINS), Neurodevelopmental Outcome, Maternal educational level, Neonatal follow-up program (NFP), Very Low Birth Weight (VLBW) infant.

\section{Introduction}

Advancements in the field of obstetrics and the care of new-born infants over the past decades have led to improved survival rates of very-low-birth-weight (VLBW) infants, which now reach more than 80\% [1]. There have also been improvements in follow-up programs for infants born at high risk for future developmental delays and disabilities with standardized neonatal follow-up programs (NFPS). This has led to a decreased incidence of children with disabilities and improved future neurodevelopmental outcomes [2,3]. Modern NFPS have expanded their services to cover the care of atrisk infants immediately after birth, unlike in the past, when such programs started to take care of infants after discharge from neonatal intensive care units (NICUs).

The services of modern NFPS include proper discharge planning systems to ensure the proper discharge of infants after fulfilling the discharge criteria according to the American Academy of paediatrics for the safety of infants after discharging 
from the hospital $[4,5]$. Cognitive deficits are the most prevalent disability among VLBW infants, who are exposed to many risk factors for neurological and developmental disabilities, such as severe intraventricular haemorrhage (IVH) [6,7], periventricular leukomalacia (PVL) [8,9], neonatal sepsis [10,11], necrotizing enterocolitis [12], and bronchopulmonary dysplasia (BPD) [13]. Being born preterm also carries high risk on its own [14].

Several studies have provided a better insight about the influence of maternal education on neurodevelopmental outcomes of children [15-19]. Chevalier et al [15] reveal a positive correlation between economic status and generations. Behavior and decisions of children are affected by their parents through preferences, genetic environment and genetic transmission. Harding et al [16] have shown positive effects of maternal education on sons' skills and health status but no effects of paternal education.

In the context of nutritional status, Menezes [18] has asserted that a strong impact is possessed by mother during and before pregnancy on children's lifelong health. Similarly, early-stage activities play a crucial role in the predisposition from experimental, clinical and epidemiological studies. Another study has pinpointed the influence of maternal education level in predicting cognitive, language, and motor outcome among preterm infants. The study has shown a positive sign of maternal education level in neurodevelopmental consequences outcome as compared to gestational age at neonatal and birth morbidities [19].

The influence of socio-demographic factors such as maternal education on the development of term and preterm infants born at high risk is well established. This has been well documented in many European studies, which illustrate the significance of parental education level and gestational age on cognitive outcomes during childhood [20-23]. Therefore, the purpose of this study is to analyse whether there is an influence of maternal education level on the long-term development of Saudi VLBW infants, similar to what has been found in developed countries, while considering cultural and sociodemographic differences. In addition, this study aims to explore different morbidities to find out which ones are significantly associated with poor outcomes.
The novelty of this research is clearly signified by undertaking Saudi Arabia as its study area. The findings will be beneficial in making comparison between developed and developing countries regarding the influence of maternal education level on the neurodevelopmental outcomes. Similarly, this research will open platform for other developing countries to study the influence of maternal education level among pre-term infants.

\section{Literature Review}

Previously, the influence of maternal education level on long-term and neurodevelopmental screening outcome has been addressed extensively. For instance, Etherington et al have examined the correlation between mental health and education of mothers, and the emotional and behavioral functioning of adolescents [24]. The study has collected data from 363 participants through 8 children's rehabilitation centers. The data was analyzed through logistic regression models. The findings have revealed that clinical signs of inattention/hyperactivity would be emerged among girls as compared to boys after one year due to the presence of health condition. Collins et al have determined improvements in cognitive outcome among infants receiving a high-docosahexaenoic acid than standard-DHA diet [25]. A multicenter randomized controlled trial has included 626 participants from 5 Australian tertiary hospitals from 2008 to 2013. The results have indicated that supplementing the diets of preterm infants with a DHA dose of approximately $1 \%$ total fatty acids from the age of 2-4 days until term corrected age showed no evidence of benefit at 7 years' corrected age.

singal et al have investigated short-term and longterm physical, mental and neurodevelopmental outcomes of children exposed to antidepressents or maternal depression during pregnancy [26]. The data was collected for the prenatal period, first trimester, second trimester and the third trimester children from 1996 to 2014. The study has analyzed the data collected through multivariate regression modelling to determine adverse birth and neonatal outcomes and adverse initial childhood outcomes. The results have indicated that prenatal exposure to antidepressant medications is correlated with low birth weight, low Apgar scores, respiratory distress, preterm birth, persistent pulmonary hypertension 
and congenital malformations. Similarly, initial childhood education challenges, adverse early childhood outcomes, diagnosis of mental disorders and diagnosis of neurodevelopmental disorders are associated with neurodevelopmental outcomes of children.

Woythaler et al have assessed the neurodevelopmental consequences of late preterm infants from infancy to school age in a longitudinal cohort study [27]. In addition, the study intends to determine forecasted earlier developmental testing values than school-age testing. The study has included 4900 full-term and 950 late preterm infants from schools. The results have shown that higher odds of having lower mean scores of total school readiness (TSRS) were found among late preterm infants with worse total school readiness score. Moreover, findings have confirmed that the positive predictive value of a child was $10.4 \%$ at kindergarten. Over the study interval, mostly infants have enhanced their score ranking at kindergarten.

Soraisham et al have compared the neurodevelopmental consequences of infants at 18 to 21 months corrected age, receiving room air at the resuscitation [28]. A retrospective cohort study has been used to compare neonatal and neurodevelopmental consequences undertaking 1509 infants before 29 weeks gestation. The findings have shown that 483 infants received intermediate oxygen concentrations, 445 received room air and 581 received $100 \%$ oxygen. The study has found insignificant differences between the neurodevelopmental impairment as compared to infants that received room air.

Deardorff et al have examined the association between child behaviors and prepregnancy BMI at ages 9-11 with respect to gender and race [29]. A longitudinal survey has been conducted by including 2952 mothers and 5660 children considering their developmental information at assorted time points. The results have shown that boys exhibit higher total behavior problems index (BPI) and externalizing scores whose mothers had higher prepregnancy weights. Moreover, findings have shown the association between prepregnancy underweight with higher total BPI of boys.

\section{Material and Methods}

Objectives and Outcomes
The primary objective of this study was to analyse the relationship between the level of maternal education and neurodevelopmental screening outcome according to the Bayley Infant Neurodevelopmental Screener (BINS). BINS is a developmental screening measure that provides an alternative approach to acquire an extensive evaluation for infants 3 to 24 months of age. A wide range of health professionals have administered this screening tool. Previously, several studies have used BINS for neurodevelopmental screening among preterm and young children [30-33]. In this regard, the subjects were Saudi infants with a corrected age of 21-24 months, who were born with a birth weight of 1000-1500 grams. The secondary objective of this study was to examine the association between morbidities, long-term outcome, and neurodevelopmental risk of delay.

The study has analysed the influence of maternal educational level on the neurodevelopmental screening outcome using the BINS score. BINS is a valid screening test that was developed in 1995, and is suitable for high-risk infants, including those with extremely low birth weight. It takes only 10 minutes for each patient, which makes it suitable for busy clinics. If used by trained professionals with proper scoring according to the BINS manual and practical training, it is considered as one of the most reliable screening tests developed thus far.

The results are interpreted as low, moderate, or high risk for future neurodevelopmental delays. If the score is low, it means that the infant will be $100 \%$ normal in the future. If the score is moderate or high, there is a $50 \%$ chance that the infant will be normal, and there is a need for definitive developmental evaluation by other standard tools such as the second or third editions of the Bayley scales. The study has divided the patients into normal and abnormal groups [34]. In our hospital, there is a wellestablished NFP that screens all infants who are at risk using BINS. Those with an abnormal score are further evaluated using the Gesell Schedule of Child Development at a corrected age of 24-36 months [35].

\section{Sample Description}

This study has retrospectively collected data from infants born in the period of 2005 to 2016 with birth weights of 1000-1500 grams who completed NFP in King Khalid University Hospital in Riyadh until 
corrected ages of 21-24 months. Data were collected from prospectively entered database of all patients recruited in the NFP. Currently, the total Saudi population is more than $20,000,000$ while total population of Riyadh is $8,000,000$. A total of $42,000-$ 48,000 deliveries are undertaken during the period of study in the hospital. In order to define sample size, the study has selected 4800 babies below 1500 grams at birth admitted to NICU during the period of 2005 to 2016. A total of 122 infants below 1500 grams were selected as a sample size based on power size (80\%) and 95\% confidence interval. This study has explored the demographic and clinical characteristics of all included infants. The incidences of the following morbidities were calculated: hypoxic ischemic encephalopathy (HIE), intraventricular haemorrhage (IVH), periventricular leukomalacia $(P \vee L)$, retinopathy of prematurity (ROP), bronchopulmonary dysplasia (BPD), persistent pulmonary hypertension (PPHN), necrotizing enterocolitis (NEC), patent ductus arteriosus (PDA), and sepsis.

The long-term outcomes defined as blindness, deafness, and cerebral palsy. Blindness and deafness were measured by clinical evaluation as well as brain-stem-evoked potentials. At the corrected age of 21-24 months, the BINS test results were obtained and interpreted as low (no risk for neurodevelopmental delay), moderate (moderate risk for neurodevelopmental delay), and high (high risk for neurodevelopmental delay). The infants were divided into two groups: normal (low BINS score) and abnormal (moderate or high BINS score). Mothers were classified into two groups based on their achieved level of education according to the international standard classification of education (ISCED) as group $\mathrm{H}$ (higher education than secondary school education) and group $\mathrm{N}$ (normal or lowsecondary school education and below). Missing data were manually collected from patients' files. All outborn babies, infants with congenital anomalies that would definitely lead to adverse developmental outcomes, and those with incomplete data were excluded from the study.

\section{Statistical Methods}

Statistical data were entered into Microsoft Excel and analysed using SPSS software version 19.0. Descriptive statistics were obtained by calculating the frequency, percentages, means, and standard deviations (SDs). Descriptive statistics were used to identify the most likely morbidity associated to the adverse long-term outcome at age 21-24 months. Sample characteristics were summarized using the mean \pm SD for numerical data and using frequency and percentages for categorical data. Chi-square or Fisher's exact tests were used for comparison between discrete variables. $P$ values $<0.05$ were considered statistically significant.

\section{Results}

A total of 122 infants who fulfilled the study criteria were included. The demographic and clinical characteristics of the patients are summarized in table 1.

Table 1: Demographic and Clinical Characteristics of Patients

\begin{tabular}{|c|c|}
\hline Total number of patients & 122 \\
\hline Gestational age (weeks) (mean \pm SD) & $29.57 \pm 1.61$ \\
\hline Range (weeks) & $26-34$ \\
\hline Gender & No $(\%)$ \\
\hline Male & $70(57.4)$ \\
\hline Female & $52(42.6)$ \\
\hline Weight (grams) & $1265 \pm 154.27$ \\
\hline Range (grams) & $1000-1500$ \\
\hline Hypoxic Ischemic Encephalopathy (HIE) & $0(0)$ \\
\hline \multicolumn{2}{|l|}{ Intraventricular Haemorrhage (IVH) } \\
\hline No & $114(93.4)$ \\
\hline Grade I & $1(0.80)$ \\
\hline Grade II & $2(1.6)$ \\
\hline Grade III & $3(2.5)$ \\
\hline Grade IV & $2(1.6)$ \\
\hline \multicolumn{2}{|l|}{ Morbidities } \\
\hline Periventricular leukomalacia (PVL) & $0(0)$ \\
\hline Retinopathy of prematurity (all stages) & $21(17.2)$ \\
\hline Bronchopulmonary dysplasia (BPD) & $13(10.7)$ \\
\hline
\end{tabular}




\begin{tabular}{|l|l|}
\hline Persistent pulmonary hypertension (PPHN) & $3(2.5)$ \\
\hline Necrotizing enterocolitis (NEC) & $13(10.7)$ \\
\hline Sepsis/Men & $23(18.9)$ \\
\hline Patent ductus arteriosus (PDA) & $28(23.0)$ \\
\hline Long-term Outcomes & \\
\hline Blindness & $0(0)$ \\
\hline $\begin{array}{l}\text { Deafness } \\
\text { Cerebral palsy (CP) }\end{array}$ & $1(0.80)$ \\
\hline $\begin{array}{l}\text { Bayley infant's neurodevelopmental screener } \\
\text { (BINS) at 21-24 months corrected age }\end{array}$ & $3(2.5)$ \\
\hline $\begin{array}{l}\text { Normal (low) } \\
\text { Abnormal (moderate + high) }\end{array}$ & $60(49.2)$ \\
\hline
\end{tabular}

The mean gestational age was 29.57 weeks, and the mean birth weight 1265 grams. There was a predominance of males (57\%). None of the 122 infants included had HIE or PVL. Only one infant developed deafness, and there were no reported cases of blindness.

There was no statistically significant association between the level of maternal education and neurodevelopmental screening outcome at the age of 21-24 months according to BINS ( $p=0.149$; Table 2 ).

Table 3: Association between morbidities and adverse outcomes.
Table 2: Association between Maternal Education and Bayley Infant Neurodevelopmental Screener (BINS) Score

\begin{tabular}{|c|c|c|c|c|}
\hline & & & BINS 21-24 & $p$ value \\
\hline \multirow{3}{*}{$\begin{array}{l}\text { Maternal } \\
\text { education }\end{array}$} & & $\begin{array}{l}\text { Normal } \\
(\text { low })(n=60)\end{array}$ & $\begin{array}{l}\text { Abnormal } \\
\text { (moderate } \\
+ \text { high) } \\
(n=62)\end{array}$ & \multirow{3}{*}{0.149} \\
\hline & $\begin{array}{l}\text { High (more } \\
\text { than } \\
\text { secondary) } \\
(n=84)\end{array}$ & $45(53.60)$ & $39(46.40)$ & \\
\hline & $\begin{array}{l}\text { Low } \\
\text { (secondary } \\
\text { school and } \\
\text { below) } \\
(n=38)\end{array}$ & $15(39.50)$ & $23(60.50)$ & \\
\hline
\end{tabular}

For the secondary outcome, the study has explored the association between morbidities and long-term outcomes to see which ones are highly associated with adverse long-term and neurodevelopmental outcomes (Table 3). BPD was highly associated with cerebral palsy $(p=0.001)$ and an abnormal BINS score at the age 21-24 months $(p=0.010)$. There was a potentially significant association between patient ductus arteriosus (PDA) and an abnormal BINS score at the age $21-24$ months $(p=0.040)$.

\begin{tabular}{|c|c|c|c|c|c|c|c|c|c|c|}
\hline & & Deafness & & $p$ value & $\mathrm{CP}$ & & $p$ value & BINS 21-24 & & $p$ value \\
\hline \multirow{6}{*}{ AS } & & NO (121) & YES $(n=1)$ & \multirow{6}{*}{$>0.05$} & NO $(n=118)$ & YES $(n=3)$ & \multirow{6}{*}{0.153} & $\begin{array}{l}\text { Normal (Low) } \\
(n=60)\end{array}$ & $\begin{array}{l}\text { Not Normal } \\
\text { (Medium +High) } \\
(n=62)\end{array}$ & \multirow{6}{*}{0.491} \\
\hline & 5 & $1(0.80)$ & $0(0.0)$ & & $1(0.80)$ & $0(0.0)$ & & $0(0.0)$ & $1(1.60)$ & \\
\hline & 6 & $4(3.30)$ & $0(0.0)$ & & $3(2.50)$ & $1(33.30)$ & & $1(1.70)$ & $3(4.90)$ & \\
\hline & 7 & $14(11.70)$ & $0(0.0)$ & & $14(11.90)$ & $0(0.0)$ & & $5(8.30)$ & $9(14.80)$ & \\
\hline & 8 & $51(42.50)$ & $0(0.0)$ & & $50(42.40)$ & $1(33.30)$ & & $27(45.0)$ & $24(39.30)$ & \\
\hline & 9 & $50(41.70)$ & $1(100.0)$ & & $50(42.40)$ & $1(33.30)$ & & $27(45.0)$ & $24(39.30)$ & \\
\hline \multirow{4}{*}{ IVH } & No & $113(93.40)$ & $1(100.0)$ & \multirow{4}{*}{$>0.05$} & $112(94.10)$ & $2(66.70)$ & \multirow{4}{*}{0.12} & $57(95.0)$ & $57(91.90)$ & \multirow{4}{*}{0.368} \\
\hline & Grade I & $1(0.80)$ & $0(0.0)$ & & $1(0.80)$ & $0(0.0)$ & & $0(0.0)$ & $1(1.60)$ & \\
\hline & Grade II & $2(1.70)$ & $0(0.0)$ & & $2(1.70)$ & $0(0.0)$ & & $2(3.30)$ & $0(0.0)$ & \\
\hline & Grade III & $3(2.50)$ & $0(0.0)$ & & $3(2.50)$ & $0(0.0)$ & & $1(1.70)$ & $2(3.20)$ & \\
\hline
\end{tabular}




\begin{tabular}{|c|c|c|c|c|c|c|c|c|c|c|}
\hline & Grade IV & $2(1.70)$ & $0(0.0)$ & & $1(0.80)$ & $1(33.30)$ & & $0(0.0)$ & $2(3.20)$ & \\
\hline \multirow{2}{*}{ ROP } & No & $100(82.60)$ & $1(100.0)$ & \multirow{2}{*}{$>0.05$} & 99 (83.20) & $2(66.70)$ & \multirow{2}{*}{0.436} & $53(88.30)$ & $48(77.40)$ & \multirow{2}{*}{0.11} \\
\hline & Stage 1 & $21(17.40)$ & $0(0.0)$ & & $20(16.80)$ & $1(33.30)$ & & $7(11.70)$ & $14(22.60)$ & \\
\hline \multirow{2}{*}{ BPD } & No & $109(90.10)$ & $0(0.0)$ & \multirow{2}{*}{0.107} & $109(91.60)$ & $0(0.0)$ & \multirow{2}{*}{$0.001^{*}$} & $58(96.70)$ & $51(82.30)$ & \multirow{2}{*}{$0.010^{\star}$} \\
\hline & Yes & $12(9.90)$ & $1(100.0)$ & & $10(8.40)$ & $3(100.0)$ & & $2(3.30)$ & $11(17.70)$ & \\
\hline \multirow{2}{*}{ PPHN } & No & $118(97.50)$ & $1(100.0)$ & \multirow{2}{*}{$>0.05$} & $116(97.50)$ & $3(100.0)$ & \multirow{2}{*}{$>0.05$} & $58(96.70)$ & $61(98.40)$ & \multirow{2}{*}{0.616} \\
\hline & Yes & $3(2.50)$ & $0(0.0)$ & & $3(2.50)$ & $0(0.0)$ & & $2(3.30)$ & $1(1.60)$ & \\
\hline \multirow{2}{*}{ NEC } & No & $108(89.30)$ & $1(100.0)$ & \multirow{2}{*}{$>0.05$} & 106 (89.10) & $3(100.0)$ & \multirow{2}{*}{$>0.05$} & $51(85.0)$ & $58(93.50)$ & \multirow{2}{*}{0.126} \\
\hline & Yes & $13(10.70)$ & $0(0.0)$ & & $13(10.90)$ & $0(0.0)$ & & $9(15.0)$ & $4(6.50)$ & \\
\hline \multirow{2}{*}{$\begin{array}{l}\text { Sep/ } \\
\text { Men }\end{array}$} & No & $98(81.0)$ & $1(100.0)$ & \multirow{2}{*}{$>0.05$} & $96(80.70)$ & $3(100.0)$ & \multirow{2}{*}{$>0.05$} & $50(83.30)$ & $49(79.0)$ & \multirow{2}{*}{0.544} \\
\hline & Yes & $23(19.0)$ & $0(0.0)$ & & $23(19.30)$ & $0(0.0)$ & & $10(16.70)$ & $13(21.0)$ & \\
\hline \multirow{2}{*}{ Dysm } & No & $119(98.30)$ & $1(100.0)$ & \multirow{2}{*}{$>0.05$} & $117(98.30)$ & $3(100.0)$ & \multirow{2}{*}{$>0.05$} & $58(96.70)$ & $62(100.0)$ & \multirow{2}{*}{0.24} \\
\hline & Yes & $2(1.70)$ & $0(0.0)$ & & $2(1.70)$ & $0(0.0)$ & & $2(3.30)$ & $0(0.0)$ & \\
\hline \multirow{2}{*}{ PDA } & No & $93(76.90)$ & $1(100.0)$ & \multirow{2}{*}{$>0.05$} & $92(77.30)$ & $2(66.70)$ & \multirow{2}{*}{0.546} & $51(85.0)$ & $43(69.40)$ & \multirow{2}{*}{$0.040^{*}$} \\
\hline & Yes & 28 (23.10) & $0(0.0)$ & & $27(22.70)$ & $1(33.30)$ & & 9 (15.0) & $19(30.60)$ & \\
\hline
\end{tabular}

\section{Discussion}

The results have shown a better understanding toward the level of maternal education on long-term and neurodevelopmental screening outcomes. The study lacks to find a significant association between the level of maternal education and neurodevelopmental screening outcome at the age of 21-24. In contrast, findings have indicated a positive and significant association between morbidities and long-term outcomes with adverse outcomes. The findings have concurred with previous studies. A study conducted by John [34] indicated that the incidences of BPD, ROP, NEC, grades 3 and 4 $\mathrm{IVH}$, and PDA $(10.7 \%, 17.2 \%, 10.7 \%, 4 \%$, and $23 \%$, respectively) in our study were within the reported international ranges for infants less than 1500 grams at birth. The sepsis rate (18.9\%) was higher than international reports. Only one infant developed deafness, but there were no reported cases of blindness. In contrast, this study has tried to minimize variants that could adversely affect the purpose of the study, such as congenital anomalies and a wide range of birth weight, as we did not include babies weighing less than 1000 grams.

Another study has shown that parents of at-risk infants are completely dependent on family support, which is very strong in this country. There are no early intervention programs for family-centred care (FCC) in Saudi Arabia, which has a rather hospitalcentred care system [33]. Similarly, it has been verified that association between sex treatment interaction on function and behaviour is based on the high-DHA diet as compared to standard-DHA diet. 25 In the context of morbidities, it has been examined that low birth weight, respiratory distress, persistent pulmonary hypertension, Apgar scores of less than 5 at 5 minutes of age, and congenital malformations are associated with antidepressant medications. Morrow et al [13] have shown that pulmonary function tests were found among 40 verylow-birth-weight infants. Similarly, the findings have revealed that patients were at a mean corrected gestational age of 34.9 weeks. Ardilla et al [20] have indicated that parents' educational level have significant effect is highly dependent on the public 
and private life of school children. The study has emphasized that the development of executive functions is presented to understand the influence of environmental factors. Woss et al [21] have asserted that a decreased composite intelligence quotient in children is highly associated with a low maternal educational background. It has been hypothesized that maternal education level may not play a role in the long-term neurodevelopmental outcome because the family structure and community setup in Saudi Arabia are completely different from developed countries.

\section{Conclusion}

There was no significant influence of the level of maternal education on neurodevelopmental screening outcomes of VLBW infants at the corrected age of 21-24 months. BPD was the strongest predictor of adverse neurodevelopmental outcomes. As expected, this study showed no influence of maternal education on neurodevelopmental outcomes. BPD was the morbidity with the highest association with adverse long-term and neurodevelopmental outcomes. This might be explained by sickness within the first months after discharge with frequent visits to the emergency room or frequent admissions and suboptimal growth, which ultimately affect the neurodevelopmental process. Thereby, women with low level maternal education is one of the major limitations for this study as signified from insignificant association between maternal education and neurodevelopmental outcomes. The study has only examined association between the level of maternal education on neurodevelopmental screening outcomes at 21-24 months. However, future studies should conduct a comparative analysis by undertaking groups at different time periods.

\section{Acknowledgment}

Special thanks to the neonatal follow-up team, Dr. Amull Faris and Dr. Rozina Banoo, for their great effort in data collection and entry.

\section{Conflict of interest}

The author declares no conflict of interest.

\section{Copyrights}

C2019 Badr Hasan Sobaih; licensee OA Journal of Clinical Case Reports. This is an Open Access article distributed under the terms of the Creative Commons Attribution License (http:// creativecommons.org/licenses/by/4.0), which permits unrestricted use, distribution, and reproduction in any medium, provided the original work is properly credited.

\section{References}

1. Grisaru-Granovsky, Boyko V, Lerner-Geva L, et al. (2018) The mortality of very low birth weight infants: the benefit and relative impact of changes in population and therapeutic variables. J Matern Fetal Neonatal Med. 20:1-9.

2. Hack M, Wilson-Costello D, Friedman H, et al. (2000) Neurodevelopment and predictors of outcomes of children. Arch Pediatr Adolesc Med. 154:725-731.

3. Wilson-Costello D, Friedman H, Minich N, et al. (2007) Improved neurodevelopmental outcomes for extremely low birth weight infants in 2000-2002. Pediatrics. 119:37-45.

4. Vohr BR, O'Shea M, Wright LL. (2003) Longitudinal multicenter follow-up of high-risk infants: why, who, when, and what to assess. Semin Perinatol. 27:333-342.

5. Wang CJ, McGlynn EA, Brook RH. (2006) Quality-of-care indicators for the neuro-developmental follow-up of very low birth weight children: results of an expert panel process. Pediatrics. 117:2080-2092.

6. Testoni D, Hornik CP, Guinsburg R, et al. (2018) Early lumbar puncture and risk of intraventricular hemorrhage in very low birth weight infants. Early Hum Dev. 117:1-6.

7. Stoops C, Sims B, Griffin R, et al. (2016) Neonatal acute kidney injury and the risk of intraventricular hemorrhage in the very low birth weight infant. Neonatology. 110:307-312.

8. Mahendran A, Engel M, Ahlers-Schmidt CR, et al. (2017) Neuroimaging practices in very low birth weight neonates. J Clin Neonatol. 6:75.

9. Kersbergen KJ, De Vries LS, Groenendaal F, et al. (2015) Corticospinal tract injury precedes thalamic volume reduction in preterm infants with cystic periventricular leukomalacia. J Pediatr. 167:260-268.

10. Bizzarro MJ, Shabanova V, Baltimore RS, et al. (2015) Neonatal sepsis 2004-2013: the rise and fall of coagulase-negative staphylococci. J Pediatr. 166:1193-1199.

11. Stoll BJ, Hansen NI, Bell EF, et al. (2015) Trends in care practices, morbidity, and mortality of extremely preterm neonates, 1993-2012. JAMA. 314:1039-1051.

12. Velazco CS, Fullerton BS, Hong CR, et al. (2018) Morbidity and mortality among "big" babies who develop necrotizing enterocolitis: A prospective multicenter cohort analysis. J Pediatr Surg. 53:108-112.

13. Morrow DK, Schilling D, MCEvoy CT. (2015) Response to bronchodilators in very preterm infants with evolving bronchopulmonary dysplasia. Res Rep Neonatol. 5:113.

14. Marlow N, Wolke D, Bracewell MA, et al. (2005) Neurologic and developmental disability at six years of age after extremely preterm birth.N Engl J Med. 352: 9-19.

15. Chevalier A, Harmon C, O'Sullivan V, et al. (2013) The impact of parental income and education on the schooling of their children. IZA J Labor Econ. 2:8.

16. Harding JF, Morris PA, Hughes D. (2015) The relationship between maternal education and children's academic outcomes: A theoretical framework. J Marriage Fam. 77: 60-76.

17. Lundborg P, Nilsson A, Rooth DO. (2014) Parental education and offspring outcomes: evidence from the Swedish compulsory School Reform. Am Econ J Appl Econ. 6:253-278.

18. Menezes ED. (2015) Maternal education and child health status: Comparative analysis of three Latin America countries (Doctoral dissertation, Rutgers The State University of New Jersey-New Brunswick). 2:1-74.

19. Patra K, Greene MM, Patel AL, et al. (2016) Maternal education level predicts cognitive, language, and motor outcome in preterm infants in the second year of life. Am J Perinatol. 33:738. 
20. Ardilla A, Roselli M, Matute E, et al. (2005) The influence of the parents, educational level on the development of executive functions. Dev Neuropsychol. 28:539-560.

21. Woss W, Jungmann T, Wachtendorf M, et al. (2012) Long-term cognitive outcomes of extremely low-birth-weight infants: the influence of the maternal educational background. Acta Pediatrica. 101:569-574.

22. Leonard C, Piecuch R, Cooper B. (2001) Use of the Bayley infant's neurodevelopmental screener with low birth weight infants. J Pediatr Psychol. 26:33-40.

23. Sobaih B. (2012) Neonatal follow-up program: where do we stand. Sudan J Paediatr. 12:21-26.

24. Etherington N, McDougall J, DeWit D, et al. (2016) Maternal factors and the emotional and behavioural functioning of adolescents with chronic health conditions. Disabil Rehabil. 38:1359-1369.

25. Collins CT, Gibson RA, Anderson PJ, et al. (2015) Neurodevelopmental outcomes at 7 years' corrected age in preterm infants who were fed high-dose docosahexaenoic acid to term equivalent: a follow-up of a randomised controlled trial. BMJ Open. 5:e007314.

26. Singal D, Brownell M, Chateau D, et al. (2016) Neonatal and childhood neurodevelopmental, health and educational outcomes of children exposed to antidepressants and maternal depression during pregnancy: protocol for a retrospective population-based cohort study using linked administrative data. BMJ Open. 6:e013293.

27. Woythaler M, McCormick MC, Mao WY, et al. (2015) Late preterm infants and neurodevelopmental outcomes at kindergarten. Pediatrics. 136:424-431.

28. Soraisham AS, Rabi Y, Shah PS, et al. (2017) Neurodevelopmental outcomes of preterm infants resuscitated with different oxygen concentration at birth. J Perinatol. 37:1141.
29. Deardorff J, Smith LH, Petito L, et al. (2017) Maternal Prepregnancy Weight and Children's Behavioral and Emotional Outcomes. Am J Prev Med. 53:432-440.

30. McCarthy AM, Wehby GL, Barron S, et al. (2012) Application of neurodevelopmental screening to a sample of South American infants: the Bayley Infant Neurodevelopmental Screener (BINS). Infant Behav Dev. 35:280-294.

31. Soysal AS, Gucuyener K, Ergenekon E, et al. (2014) The Prediction of Later Neurodevelopmental Status of Preterm Infants at Ages 7 to 10 Years Using the Bayley Infant Neurodevelopmental Screener. J Child Neurol. 29:1349-1355.

32. Wehby GL, Trujillo AJ. (2017) Differences in early cognitive and receptive-expressive neurodevelopment by ancestry and underlying pathways in Brazil and Argentina. Infant Behav Dev. 46:100-114.

33. Mukherjee SB, Aneja S, Krishnamurthy V, et al. (2014) Incorporating developmental screening and surveillance of young children in office practice. Indian J Pediatr. 51:627-635.

34. John M. (2011) Survival and long-term neurodevelopmental outcome of the extremely preterm infant. A Systemic review. Saudi Med J. 32:885-894

35. Al-Jadid M. (2013) Disability in Saudi Arabia. Saudi Med J. 34:453-460. 